\title{
Low-dose CT screening for lung cancer in Brazil: a study protocol
}

\author{
Rastreamento de câncer de pulmão por meio de TC de \\ baixa dosagem no Brasil: protocolo de pesquisa
}

\author{
Ricardo Sales dos Santos, Juliana Franceschini, Fernando Uliana Kay, \\ Rodrigo Caruso Chate, Altair da Silva Costa Júnior, \\ Fernando Nunes Galvão de Oliveira, André Luiz Cavalcante Trajano, \\ José Rodrigues Pereira, Jose Ernesto Succi, Roberto Saad Junior
}

\section{To the Editor:}

Because of the lack of studies aimed at screening for lung cancer (LC) in the Brazilian population, a project that is integrated into the Program for the Support of the Institutional Development of the Brazilian National Ministry of Health Unified Health Care System and whose objective is to evaluate the efficacy of low-dose CT (LDCT) scans of the chest in screening for LC was launched. The objective of the present letter was to describe the design and methods of the Projeto de Detecção Precoce do Câncer de Pulmão (ProPulmão, Project for Early Detection of Lung Cancer), which was approved by the Research Ethics Committee of the Instituto Israelita de Ensino e Pesquisa do Hospital Albert Einstein (Protocol no. CAAE 02087012.1.0000.0071).

For the development of the project, the final sample will comprise 1,000 individuals recruited as of 2013 via public calls in vehicles of communication in the greater metropolitan area of São Paulo, as well as via partnerships with other community care services. The sample size was calculated on the basis of previous international studies addressing this issue. ${ }^{(1)}$

The inclusion criteria are as follows ${ }^{(2)}$ : having no respiratory symptoms; being in the 55-74 year age bracket; being a smoker with a smoking history of at least 30 pack-years or having been a former smoker for 15 years at most; and agreeing to participate in the study by giving written informed consent. The exclusion criteria are as follows: being unable to undergo CT scans; being pregnant; having previously undergone radiation therapy to the chest; and having severe chronic disease, such as cardiovascular disease, lung disease, liver disease, kidney disease, and metabolic disease.
The primary outcome measure is early diagnosis of LC. Nevertheless, participants will undergo a multidisciplinary evaluation for smoking-related diseases and infectious diseases that are common in Brazil, such as tuberculosis.

At the initial visit, demographic and smoking history data will be collected; health-related quality of life will be assessed by the Medical Outcomes Study 36-item Short-form Health Survey ${ }^{(3)}$; the presence of anxiety or depression will be determined by the hospital anxiety and depression scale ${ }^{(4)}$; and the presence of nicotine dependence in current smokers will be determined by the Fagerström test. ${ }^{(5)}$

After the initial evaluation, individuals will be referred for LDCT screening, the scans being analyzed by two radiologists with experience in thoracic diseases. Indeterminate pulmonary nodules $\geq 4 \mathrm{~mm}$ in size will be evaluated by a medical team comprising radiologists, pulmonologists, and thoracic surgeons, who will decide on the follow-up strategy (Chart 1).

In cases of solid nodules $>8 \mathrm{~mm}$ in size, radiological features alone are not enough to distinguish between benign and malignant nodules. Therefore, it is important to estimate the clinical probability of malignancy. This estimation is known as pre-test probability and aids in reducing interobserver variability regarding the probability of malignancy. A multivariate logistic regression model developed at Mayo Clinic $^{(6)}$ on the basis of six independent predictors of malignancy-including patient age (in years), being a smoker or former smoker, having a history of extrathoracic cancer diagnosed more than 5 years prior, nodule diameter (in $\mathrm{mm}$ ), presence of spicules, and upper lobe involvement-will be used in the study. 
Chart 1 - Follow-up strategies to monitor high-risk patients for solid nodules, ground-glass opacity, and nonsolid nodules, based on the National Comprehensive Cancer Network Guidelines for Lung Cancer Screening and on the Fleischner Society guidelines. ${ }^{a}$

\begin{tabular}{|c|c|}
\hline Size & Solid nodules in high-risk patients \\
\hline$\leq 4 \mathrm{~mm}$ & $\begin{array}{l}\text { Follow-up LDCT scans should be taken after one year. If there are no } \\
\text { changes, patients should undergo annual follow-up examinations. }\end{array}$ \\
\hline$>4 \mathrm{~mm}$ and $\leq 6 \mathrm{~mm}$ & $\begin{array}{l}\text { Follow-up LDCT scans should be taken after } 6 \text { months and after one year. } \\
\text { If there are no changes, patients should undergo LDCT after } 18 \text { months } \\
\text { and after } 24 \text { months. }\end{array}$ \\
\hline$>6 \mathrm{~mm}$ and $\leq 8 \mathrm{~mm}$ & $\begin{array}{l}\text { Follow-up LDCT scans should be taken after } 3 \text { months and after } 6 \\
\text { months. If there are no changes, patients should undergo LDCT after } 9 \\
\text { months, after } 12 \text { months, and after } 24 \text { months. If the nodule increases in } \\
\text { size, biopsy or surgical resection is recommended. }\end{array}$ \\
\hline \multirow[t]{5}{*}{$>8 \mathrm{~mm}$} & Calculate pre-test probability. Probability of malignancy: \\
\hline & - $\quad$ Low $(<5 \%)$ : serial LDCT scans \\
\hline & $\begin{array}{l}\text { - Intermediate (5-60\%): PET-CT (if negative, serial LDCT scans; if } \\
\text { positive, biopsy or surgical resection) }\end{array}$ \\
\hline & - High (> 60\%): biopsy or surgical resection \\
\hline & Ground-glass opacity and nonsolid nodules \\
\hline Pure ground-glass opacity $\leq 5 \mathrm{~mm}$ & $\begin{array}{l}\text { Follow-up LDCT scans should be taken after one year. If there are no } \\
\text { changes, patients should undergo annual follow-up examinations. If } \\
\text { the nodule increases in size or becomes solid, patients should undergo } \\
\text { LDCT after } 3 \text { months and after } 6 \text { months. Alternatively, the possibility of } \\
\text { performing a biopsy or surgical resection should be considered. }\end{array}$ \\
\hline Pure ground-glass opacity $>5 \mathrm{~mm}$ & $\begin{array}{l}\text { Follow-up LDCT scans should be taken after } 3 \text { months. If there are no } \\
\text { changes, patients should undergo annual follow-up examinations. If the } \\
\text { nodule increases in size or if there are changes in the characteristics of the } \\
\text { nodule, the possibility of performing a biopsy or surgical resection should } \\
\text { be considered. }\end{array}$ \\
\hline Part-solid nodule & $\begin{array}{l}\text { Follow-up LDCT scans should be taken after } 3 \text { months. If there are } \\
\text { no changes and the part-solid nodule is }>8 \mathrm{~mm} \text {, the possibility of } \\
\text { performing a PET-CT scan should be considered, possible follow-up } \\
\text { strategies including LDCT scans, biopsy, and surgical resection. If the } \\
\text { nodule increases in size or if there are changes in the characteristics of the } \\
\text { nodule, the possibility of performing a biopsy or surgical resection should } \\
\text { be considered. }\end{array}$ \\
\hline
\end{tabular}

LDCT: low-dose CT; and PET-CT: positron emission tomography-CT. adapted from the National Comprehensive Cancer Network, ${ }^{(7)}$ MacMahon et al., ${ }^{(8)}$ and Patel et al. ${ }^{(9)}$

After undergoing LDCT, all patients will return for a follow-up evaluation, in which the LDCT findings will be recorded and the follow-up strategy will be proposed. At that visit, current smokers will be referred to a smoking cessation program. Although participation in the program is encouraged, enrollment is voluntary.

Abnormal CT findings will be recorded on a specific form, analyzed by the expert panel, and classified on the basis of the level of suspicion of malignancy, follow-up strategies being subsequently decided on (Figure 1).

In cases of lung cancer, the nodules seen on the follow-up LDCT scans will be compared with those seen on the initial LDCT scans; the parameters for all CT scans will be the same, therefore allowing the examination of possible changes.

Subsequent visits, occurring in the second year of follow-up, will be conducted in accordance with the flowchart shown in Figure 1, specific findings in each individual in the previous year being taken into consideration (Chart 1).

The attending physician at the outpatient clinic will give the participants the results of the LDCT examinations. In addition, the medical team will inform the participants of the suspicion or diagnosis of $\mathrm{LC}$.

After diagnostic confirmation and surgical treatment (when appropriate), patients will be referred for oncological follow-up via the Brazilian 


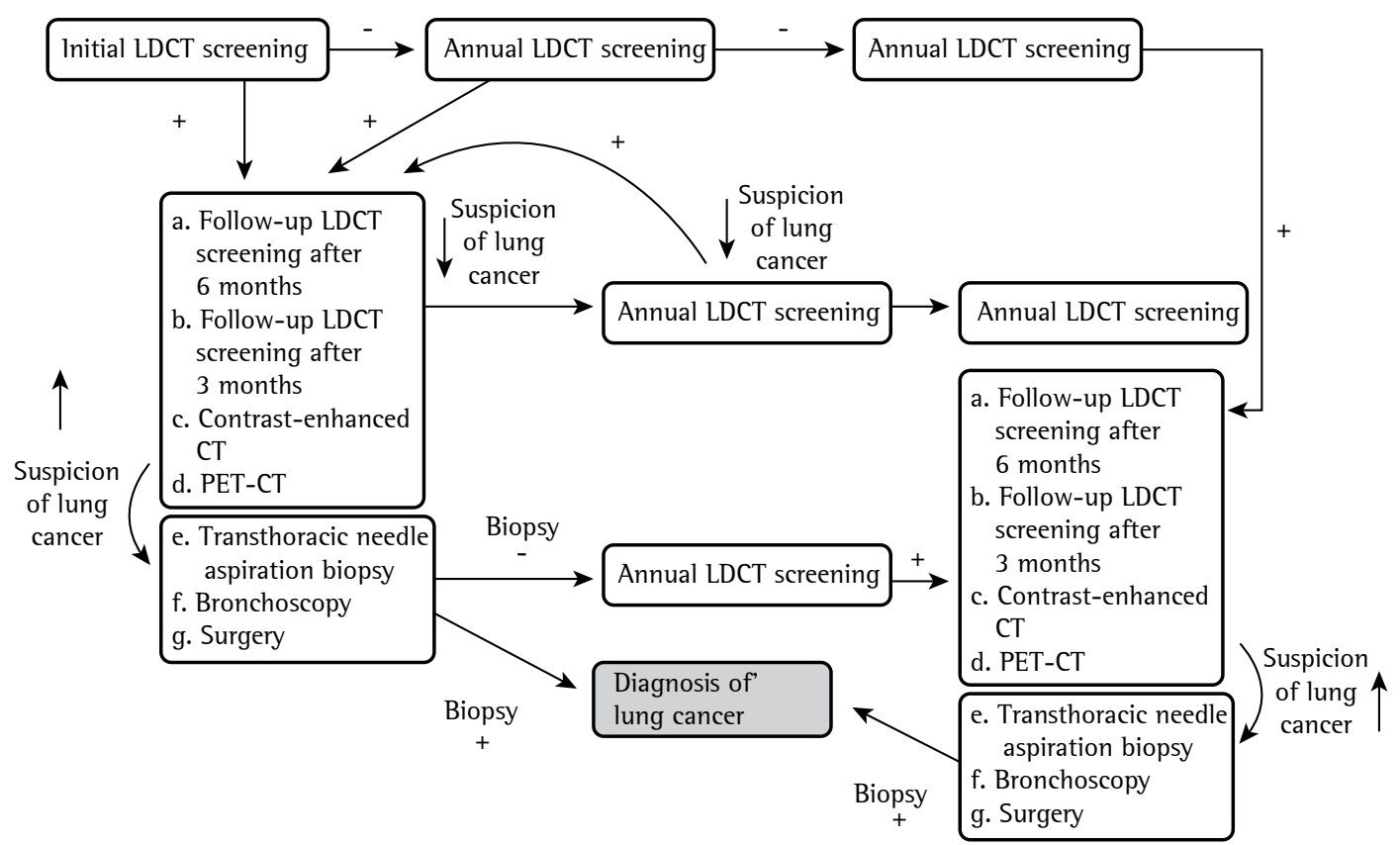

Figure 1 - Flowchart of possible follow-up strategies. LDCT: low-dose CT; and PET-CT: positron emission tomography-CT.

Unified Health Care System or the private health care system and will receive adjuvant therapy as medically indicated.

To date, there have been no studies of LDCT screening for $\mathrm{LC}$ in developing countries, in which the incidence of infectious diseases of the chest is higher. This raises many questions regarding the sensitivity and specificity of the method for LC screening.

The use of LDCT screening in Brazil is of fundamental importance because it will provide specific information for the validation of the method as a population screening tool for $\mathrm{LC}$.

\section{Ricardo Sales dos Santos}

Coordinator, Center for Minimally Invasive Thoracic Surgery, Robotics \& Bronchoscopy, Hospital lsraelita Albert

Einstein; and Principal Investigator, ProPulmão, São Paulo, Brazil

Juliana Franceschini

Researcher, ProPulmão, São Paulo, Brazil

Fernando Uliana Kay

Preceptor, University of São Paulo

School of Medicine Hospital das
Clinicas; and Physician, Department of Diagnostic Support, Hospital lsraelita Albert Einstein, São Paulo, Brazil

Rodrigo Caruso Chate

Physician, Department of Diagnostic

Support, Hospital lsraelita Albert

Einstein, São Paulo, Brazil

Altair da Silva Costa Júnior Physician in Charge of the Pediatric Thoracic Surgery Outpatient Clinic, Department of Thoracic Surgery, Federal University of São Paulo Paulista School of Medicine, São Paulo, Brazil; and Professor, Department of Thoracic Surgery, ABC School of Medicine, Santo André, Brazil

Fernando Nunes Galvão de Oliveira Oncologist, CLION/GRUPO CAM, Salvador, Brazil

André Luiz Cavalcante Trajano Thoracic Surgeon, Cardiopulmonary Institute, Salvador, Brazil 


\section{José Rodrigues Pereira Attending Pulmonologist, Portuguese Beneficent Hospital of São Paulo, São Paulo, Brazil \\ José Ernesto Succi \\ Assistant Professor, Department of Thoracic Surgery, Federal University of São Paulo Paulista School of Medicine, São Paulo, Brazil \\ Roberto Saad Junior \\ Full Professor, Santa Casa School of Medical Sciences in São Paulo, São Paulo, Brazil}

\section{References}

1. Henschke Cl, McCauley Dl, Yankelevitz DF, Naidich DP, McGuinness G, Miettinen OS, et al. Early Lung Cancer Action Project: overall design and findings from baseline screening. Lancet. 1999;354(9173):99-105. http://dx.doi. org/10.1016/S0140-6736(99)06093-6

2. Arenberg D, Kazerooni EA. Setting up a lung cancer screening program. J Natl Compr Canc Netw. 2012;10(2):277-85. PMid:22308520

3. Cicconelli R, Ferraz M, Santos W, Meinão 1, Quaresma M. Tradução para a língua portuguesa e validação do questionário genérico de avaliação da qualidade de vida SF-36 (Brasil SF-36). Rev Bras Reumatol. 1999;39(3):143-50.

4. Marcolino JA, Mathias LA, Piccinini Filho L, Guaratini AA, Suzuki FM, Alli LA. Hospital Anxiety and Depression Scale: a study on the validation of the criteria and reliability on preoperative patients. Rev Bras Anestesiol. 2007;57(1):52-62. PMid:19468618. http://dx.doi. org/10.1590/S0034-70942007000100006

5. Meneses-Gaya IC, Zuardi AW, Loureiro SR, Crippa JA. Psychometric properties of the Fagerström Test for Nicotine Dependence. J Bras Pneumol. 2009;35(1):7382. PMid:19219334. http://dx.doi.org/10.1590/ S1806-37132009000100011

6. Swensen SJ, Silverstein MD, Ilstrup DM, Schleck CD, Edell ES. The probability of malignancy in solitary pulmonary nodules. Application to small radiologically indeterminate nodules. Arch Intern Med. 1997;157(8):84955. PMid:9129544. http://dx.doi.org/10.1001/ archinte.1997.00440290031002

7. NCCN Clinical Practice Guidelines in Oncology (NCCN Guidelines). Lung Cancer Screening Version 1.2012. Fort Washington: National Comprehensive Cancer Network; 2011.

8. MacMahon H, Austin JH, Gamsu G, Herold CJ, Jett JR, Naidich DP, et al. Guidelines for management of small pulmonary nodules detected on CT scans: a statement from the Fleischner Society. Radiology. 2005;237(2):395-400. PMid:16244247. http://dx.doi. org/10.1148/radiol.2372041887

9. Patel VK, Naik SK, Naidich DP, Travis WD, Weingarten JA, Lazzaro R, et al. A practical algorithmic approach to the diagnosis and management of solitary pulmonary nodules: part 2: pretest probability and algorithm. Chest. 2013;143(3):840-6. PMid:23460161. http:// dx.doi.org/10.1378/chest.12-1487 